Vulnerability to bullying of children with autism spectrum conditions in mainstream education: A multi-informant qualitative exploration

Judith Hebron ${ }^{1}$, Neil Humphrey ${ }^{1}$ and Jeremy Oldfield ${ }^{2}$

${ }^{1}$ Manchester Institute of Education, University of Manchester, UK

${ }^{2}$ Department of Psychology, Manchester Metropolitan University, UK

Address for correspondence:

Judith Hebron

Manchester Institute of Education

University of Manchester

Oxford Road

Manchester

M13 9PL

Email: judith.hebron@manchester.ac.uk 


\title{
Vulnerability to bullying of children with autism spectrum conditions in mainstream education: A multi-informant qualitative exploration
}

\begin{abstract}
Young people with autism spectrum conditions (ASC) are widely reported by parents and teachers to be bullied by peers during their school years. Research in this area is still in its relative infancy with the majority of studies quantitative in nature. The aim of the current study was therefore to investigate vulnerability to bullying of young people with ASC in mainstream schools in England. Five pupils aged 5-13 (3 male, 2 female) were selected. Semi-structured interviews were conducted with the children (where possible), their parents and teachers to explore vulnerability to being bullied in the context of school. While none of the pupils were being seriously bullied, they were all recognised as vulnerable, especially as they grew older. Difficulties in conceptualising bullying emerged among the children, along with challenges forming and maintaining peer relationships. Behaviour difficulties risked isolating the pupils, potentially making them more vulnerable to bullies. However, school emerged as having a powerful protective role to play, with a positive ethos and zero tolerance of bullying, promotion of good relationships and communication with parents crucial in mitigating the risk of being bullied. The implications of these findings are discussed in relation to research and practice.
\end{abstract}

Keywords: autism, ASC, bullying, victimisation, risk, school 


\section{Vulnerability to bullying of children with autism spectrum conditions in mainstream education: a multi-informant qualitative exploration}

\section{Introduction}

Bullying of young people with autism spectrum conditions ${ }^{1}$ (ASC) is a serious and pernicious problem (Reid \& Batten, 2006). Fortunately, it is now attracting empirical studies nationally and internationally which have begun to shed light on prevalence and risk factors. These studies are predominantly quantitative in nature (e.g. Kloosterman, Kelley, Craig, Parker, \& Javier, 2013; Zablotsky, Bradshaw, Anderson, \& Law, 2013), meaning that there remains a need for more qualitative experiential research that can complement and extend our understanding of the phenomenon. This paper therefore contributes to existing research in the field from a qualitative, experiential standpoint. Many of its findings echo those of larger scale quantitative studies (e.g. the salience of friendship) but also permit a more in-depth exploration of bullying and issues surrounding it.

\section{Bullying and young people with ASC}

All schools in England are required to have an anti-bullying policy that complies with legislation ('Education and Inspections Act,' 2006), yet it continues to be an issue. Bullying can take both direct (e.g. fighting and name-calling) and indirect forms (e.g. spreading of rumours and shunning). While an agreed definition of bullying has yet to be achieved, Olweus' (1993) version remains widely used in the literature and is the one that informed this study: "A student is being bullied or victimised when he or she is exposed, repeatedly and

\footnotetext{
${ }^{1}$ The term "autism spectrum conditions" is used in preference to "autism spectrum disorders" in this article, as it implies a difference rather than a deficit, thereby acknowledging the strengths as well as difficulties of those with ASC (Baron-Cohen, 2012).
} 
over time, to negative actions on the part of one or more other students" (p.9). Nevertheless, differences between adults and children in understanding bullying (Smith et al., 2002), and the broad social context in which it takes place, mean that definitions need to remain fluid. The consequences of bullying are acknowledged as serious, wide-ranging and potentially long-lasting: they include detrimental effects on a child's well-being (McMahon, Reulbach, Keeley, Perry, \& Arensman, 2010), behaviour (e.g. Sourander et al., 2007) and difficulties at school (e.g. Green, Collingwood, \& Ross, 2010).

It is a point of great concern that a number of the key risk factors for being bullied bear a striking resemblance to characteristics often seen in young people with ASC, such as social vulnerability and behaviour problems (for a detailed discussion see Sreckovic, Brunsting, \& Able, 2014), with Klin, Volkmar, and Sparrow (2000) referring to this group of young people as "perfect victims" (p. 6). While research in this area is still in its relative infancy, there is a growing number of predominantly quantitative studies exploring bullying among young people with ASC and why they may be particularly vulnerable to becoming victims (e.g. Cappadocia, Weiss, \& Pepler, 2012; Sofronoff, Dark, \& Stone, 2011). Prevalence studies indicate that they are bullied frequently and more so than both their typically developing peers (Wainscot, Naylor, Sutcliffe, Tantam, \& Williams, 2008), and also those with other disabilities (Rowley et al., 2012). This has led to studies exploring risk factors which are beginning to provide an insight into vulnerabilities. These studies tend to focus on characteristics at the individual (e.g. severity of autism) and contextual level (e.g. school type). These two areas are discussed below along with an acknowledgement of their interlinking nature.

Difficulties in negotiating the social world lie at the core of ASC, and while the heterogeneity of the condition must not be ignored, young people with ASC often encounter difficulties at school, including bullying, that are social in nature. For example, Sofronoff et al. (2011) 
found social vulnerability to be a significant predictor of bullying among young people with Asperger Syndrome aged 6-16 according to parent report. In their qualitative study, Humphrey and Symes (2010b) found social support to a be useful strategy to combat bullying, although relationship issues, a lack of trust, and some of the traits associated with ASC (e.g. difficulty in making friends) complicated this according to a number of the young people involved in the study. Difficulties navigating the social world - one which becomes ever more complex with the arrival of adolescence (Locke, Ishijima, Kasari, \& London, 2010) - mean that inadvertent faux pas such as inappropriate comments or failure to understand a joke can single out the young person as 'different' leading to isolation and rejection (Humphrey \& Lewis, 2008). This in turn may make friendships more difficult to form and maintain. While friendship and friendship groups are found to be protective against bullying in the broader research field, studies of young people with ASC consistently report fewer friends and/or lower quality friendships than among their typically developing peers (e.g. Bauminger et al., 2008).

Behaviour issues have also been shown to be strongly linked to becoming the victim of bullying, with Hebron and Humphrey (2013) finding this to be the most powerful predictor of bullying among students with special educational needs and disabilities (SEND) aged 6-15 in the English school system according to parent and teacher report. However, while behaviour problems are easy to identify, finding the causes and triggers is essential: these may differ qualitatively among young people with ASC compared with their typically developing peers. For example, many young people with ASC experience sensory over- or under-sensitivity that can make apparently innocuous sounds, smells or textures intolerable and highly stressful (Leekam, Nieto, Libby, Wing, \& Gould, 2007), resulting in reactions that may appear sudden and unexpected to others. In addition, outbursts may be as a direct result of bullying, when other children antagonise a peer with ASC via subtle means - such as teasing - leading to a 
reaction which may seem completely out of proportion to the perceived trigger (Carrington \& Graham, 2001). Nevertheless, although some children with ASC may externalise their behaviour, others may internalise it, resulting in shyness, anxiety, and a reluctance (or inability) to defend themselves if approached by a bully (Cappadocia et al., 2012).

Environmental factors are also likely to play a significant role in vulnerability to bullying, and there have been calls for a more holistic and less deficit-led approach in research (e.g. Billington, 2006). Fortunately, there is a growing number of studies which include contextual risk factors, with school being one of the most salient. Indeed, a small number of qualitative studies (e.g. Sciutto, Richwine, Mentrikowski, \& Niedzwiecki, 2012) have provided an important first person insight into the school experience of young people with ASC, highlighting the importance of school in managing bullying. Children spend most of their waking hours at school, and this is therefore where most of their social interactions with peers take place. The climate of a school can have a powerful effect on bullying management and prevention, with school-wide initiatives as well as consistent attitudes from staff of great importance (Ttofi \& Farrington, 2011). Linked to this, the relationships children with ASC have with their teachers are critical, especially in terms of self-esteem (Sciutto et al., 2012). For example, in their mixed methods study, Dillon, Underwood, and Freemantle (2014) reported that young people with ASC valued positive relationships with staff, but that a negative relationship with just one teacher can have a serious detrimental effect on their attitude towards school.

With the increase in young people with ASC attending mainstream schools - approximately $70 \%$ in England (DfE, 2012) - there has been a growing focus on differences in bullying between placement types. Although there have been some conflicting findings, the majority of studies have found that bullying is more likely to take place in mainstream as opposed to special settings (e.g. Rowley et al., 2012; Zablotsky et al., 2013). Putative suggestions focus 
on larger class sizes and a less highly trained workforce, resulting in negative or stereotyped attitudes (Humphrey, 2008), along with the hidden nature of ASC. Bullying often takes place in unstructured environments where adults are not immediately present, and this may be a more common event for students in mainstream schools at break and lunchtime (Hebron \& Humphrey, 2013).

The aim of the current study was to explore areas that might contribute to or mitigate the risk of being bullied among children with ASC. While a growing quantitative evidence base indicates that this group of young people is likely to be bullied more than other young people with and without SEND, the experiences and processes involved remain underexplored. Indeed, Schroeder et al.'s (2014) recent review of research on bullying experiences among children with ASC demonstrated that quantitative questionnaire-based studies dominate the field, although a recent editorial recognised the positive contribution that rigorous qualitative research can make in this area (Bölte, 2014). A case in point is Dillon, Underwood and Freemantle's (2014) mixed methods study of the secondary school experiences of young people with ASC: although quantitative measures indicated similar experiences among young people with ASC and those in the comparison group of typically developing peers, analysis of interviews revealed differences in the way students with ASC used and regarded peer support. While still in a minority, qualitative accounts from key stakeholders (i.e. from young people with ASC, their parents and teachers) give a voice to participants and "a window into their thoughts, feelings and experiences in a field dominated by impersonal experimental studies" (Humphrey \& Lewis, 2008, p. 27), permitting a more in-depth understanding of complex issues. 


\section{Method}

\section{Design}

This was a cross-sectional qualitative study utilising semi-structured interviews for data collection. The interviews were drawn from the evaluation of a UK government-funded pilot project called Achievement for All (AfA) (Humphrey et al., 2011). The aim of AfA was to support schools and local authorities in providing improved opportunities for young people with SEND. As part of this evaluation, a number of case studies were developed to reflect the range of SEND across the participating local authorities. Interviews were conducted with the young people (where possible), their parents and teachers to gain a better understanding of factors relating to the experience of school. Five young people with ASC were part of this research strand and subsequently became the focus of the current study. Ethical approval was granted for the study by the University of Manchester Research Ethics Committee.

\section{Participants}

The five participants were selected on the basis of having a confirmed diagnosis of ASC, with consent obtained from the children, their parents and teachers. All of the participants attended mainstream schools. Anonymised outline portraits of each young person are given below:

Pupil 1: Robbie was the youngest of the focus pupils and in Years $1^{2}$ and 2 during the study. He attended a large infant school in a suburban area. In agreement with his parents and teacher he was not interviewed, as he was considered too young to fully understand the research and would therefore be unable to give informed consent. He received a primary diagnosis of ASC with ADHD when he was in Nursery (age 4). He was supported at School Action Plus, which included one to one time with a teaching assistant for much of the school

\footnotetext{
${ }^{2}$ In the English education system, pupils in Y1 are aged 5-6; Y2 6-7; Y5 9-10; Y6 10-11; Y7 11-12; and Y8 $12-$ 13 , with the school year beginning in September.
} 
day. His achievement was below age-appropriate levels at the time of the interviews, although interventions were being used to address this.

Pupil 2: Jack was in Years 5 and 6 for the study and was supported at School Action Plus. He attended a small primary school in an urban area. He had some support in class from a teaching assistant to help with literacy and numeracy, as well as speech and language support from a specialist. He was very keen on sport, which had enabled him to integrate with the other pupils in his class. There were some behavioural issues, and he was often tired during the day because of difficulties in sleeping.

Pupil 3: Samuel was in Years 5 and 6 for the study. He attended the same primary school as Jack, but was not in the same class. He was also supported at School Action Plus, although assessment for a statement was being explored. He had had some serious behavioural problems and been excluded on at least one occasion in the past for violence against a teacher. He received some support in class from a teaching assistant, as he had particular difficulty in writing. He was very articulate, with a love of physics and computer games.

Pupil 4: Georgina was in Years 5 and 6 for the study. She attended primary school in a small village. In addition to ASC, she had learning delay, dyspraxia and other medical needs. Her difficulties were identified at Nursery and she was assessed for a statement of special educational needs before starting school. She received one-to-one support throughout the school day from a teaching assistant whom she had known for many years. Georgina was not interviewed as it was felt by her mother and teacher that she would not be able to give informed consent.

Pupil 5: Francesca was the oldest of the focus pupils and the only one at secondary school. She was in Years 7 and 8 for the study and attended a comprehensive school in an urban area. She had a statement of special educational needs that had been received while at primary school. She had difficulties in English and Mathematics, and received the support of a teaching assistant in most lessons. There were no issues with behaviour or attendance.

\section{Materials and procedure}


Semi-structured interviews were chosen for the data collection as they permit flexibility and opportunities for participants to give detailed explanations and for unanticipated topics of relevance to emerge (Smith \& Osborn, 2008). This is consonant with the underlying beliefs of pragmatism that no assumption about a single truth is made; instead, it is acknowledged that personal truths are part of the individual's subjective experience of the world (Greene \& Hall, 2010). It was decided to use multiple informants, in order to explore different perspectives, thereby allowing for triangulation of data to establish areas of consensus (as well as divergence). Although it was the intention to use pupil voice as far as possible, interviews with two of the children were not possible. While alternative methods exist to promote the inclusion of children in research who have more complex communication difficulties (e.g. Talking Mats - Murphy \& Cameron, 2008), it was decided jointly with parents and teachers that it was not feasible in the current study, as the two children were not able to understand the project in sufficient detail to provide informed consent. This is of particular importance when broaching potentially upsetting topics such as bullying and relationships with others. The implications of this are discussed further in the Conclusion.

The questions asked to participants focused on the pupils' experience of bullying, as well as the broader experience of school, including relationships, behaviour, inclusion and participation in school activities. Although covering the same topics, the interview schedules were adapted slightly for each informant type (e.g. interviews with the children explored their direct experience of school, attitudes towards peers and staff; interviews with parents focused on the child at home as well as school, parental engagement, and confidence in the school to meet their child's needs; interviews with teachers focused on the child at school, interactions with peers, academic progress and home/school communication). 


\section{Analysis}

Thematic analysis was adopted for the analysis of the interviews, as "it offers an accessible and theoretically flexible approach to analysing qualitative data" (Braun \& Clarke, 2006, p. 77). Due to the embedded nature of this study, the interview questions were guided to a certain extent by the demands of the larger scale evaluation project, making the analysis initially deductive (e.g. in relation to positive relationships). However, an inductive approach was also used, meaning that unanticipated themes and nuances could be acknowledged and explored (e.g. sensory sensitivity). Braun and Clarke's (2006) analytical guidelines were followed to ensure quality and rigour of analysis. This involved six stages: familiarisation with the data, generating initial codes, searching for themes, reviewing themes, defining and naming themes, and producing the report.

\section{Results and discussion}

Four main themes related to vulnerability to bullying and the experience of school were identified (each of which contained a number of sub-themes):

- The experience of being bullied

- Patterns of behaviour

- Relationships with adults and peers

- The role of school

\section{The experience of being bullied}

In terms of understanding the concept of bullying, all of the pupils who were interviewed were able to provide a working definition. However, they had more difficulty explaining why 
someone might become a victim of bullying, with Samuel citing hair colour specifically because he'd seen it on an anti-bullying poster. It is acknowledged that his could also be the case for many children without ASC; however, it is of note that the pupils interviewed struggled to conceptualise bullying despite being able to define it, and this resonates with Luke Jackson's (2002) personal account of how it can be difficult knowing how to recognise and respond to bullying as a child with ASC.

It is of some comfort, however, that teaching staff and parents concurred in reporting that none of the pupils had experienced or were experiencing severe levels of bullying. While this may not appear congruent with trends found in the literature (e.g. Sreckovic et al., 2014), it should be remembered that this is a small-scale study that does not claim to be representative of the broader ASC population. Nevertheless, in keeping with previous research (e.g. Reid \& Batten, 2006), there was an acknowledgement that the children were vulnerable to bullying, and that increasing age was an important factor (e.g. Robbie's mother: "Nobody laughs at him or teases him yet because I think the children are too young to sort of understand anyway, but I think maybe in sort of three or four years' time”). Georgina's mother exemplifies this when describing how her daughter has not matured at the same rate as her peers and now: "When I drop her off in the morning [...] she will go over and stand next to her friends and quite often I will see them sigh and turn away as if saying 'oh Georgina is here,' and they will start talking amongst themselves and ignoring her." While this cannot be confirmed as shunning, it reflects how older children may become less tolerant over time, especially as social groupings become more complex and important (Locke et al., 2010).

Parents and teachers were more consistent in recognising minor incidents of unkindness towards the young people, such as name-calling and teasing, although there was often a discrepancy between adult and child interpretations of such incidents, with the child not realising that more subtle incidents could be bullying (e.g. Robbie's teacher: "I think he 
would [tell the teacher about it] if it was an obvious thing like if someone pushed him or kicked him, if it was something someone had said then I am not sure he would necessarily understand so may not"). However, incidents that were perceived to be relatively minor by adults could be interpreted as severe by the recipient, as noted by Samuel's mother: "[other pupils] will tease Samuel about something really small, not even significant in his life, you know, they will start saying something and he will flip and next thing you know, Samuel is in trouble." Nevertheless, it is important to keep different people's perspectives in mind in such cases, as an insignificant comment to one can be much more salient to another, especially if there are additional unknown antecedents. This highlights the enduring discrepancies in definition that exist between adults and children (Smith et al., 2002), and act as a reminder that bullying needs to be seen in context and from the perspective of the victim.

\section{Patterns of behaviour}

Behavioural difficulties have been identified as a strong predictor for being bullied (e.g. Hebron \& Humphrey, 2013), and this is likely to stem from the fact that extreme behaviour of any sort singles out a child from the peer-group, potentially making that child more difficult to approach, isolated and less likely to be protected by peers (Card, Isaacs, \& Hodges, 2008). Furthermore, a child for whom emotional regulation is problematic, who loses control or may cry more easily than others, is likely to be perceived as an easy target by bullies (Olweus, 1993).

In the interviews there was an acknowledgement that certain triggers could impact on a child's behaviour. Central to this were changes in routine and sensory overload, resulting in unbearably high levels of frustration and anxiety, and this is in keeping with previous research (e.g. Leekam et al., 2007). This was the case for all of the boys, and in particular, 
Samuel, who had recently been excluded for violent conduct (e.g. Samuel's mother: "He does not like noise, lots of people, if you give him too many commands at once he gets confused and flips out and runs off'). Similar to Carrington and Graham (2001), it appears that the frustration of not understanding a situation can trigger sudden, elevated anxiety levels that can spiral out of control.

The two girls did not have behaviour problems. However, Francesca's need to adhere to rules and routine had the potential to result in contravening unwritten rules among peers (e.g. Francesca's teacher: 'She's got a very clear view of what's right and what's wrong, and that worries her sometimes, because when some of the others are misbehaving she doesn't like that, but she doesn't want to tell on them either, because she's seen how they react when other girls have said something"). This absence of behaviour problems could be illustrative of the differences in presentation thought to exist between boys and girls with ASC (e.g. Attwood, 2007), although it is recognised that conclusions cannot be drawn from such a small sample.

Nevertheless, all of the pupils appeared to have a need for control that may be as a result of finding many aspects of the social world difficult to understand, but this could also be interpreted by others as behaving in a manipulative or controlling manner. For example, Georgina's teacher stated that: "she doesn't take no for an answer very easily. You have to be very firm with her and she'll keep on." Similarly, Samuel's teacher described how "he will only want to do one thing and then he won't let the others take turns and that is a problem." In both cases these reactions may be interpreted negatively to staff and parents, making a need for control and negative behaviour difficult to distinguish (MacNeil, Lopes, \& Minnes, 2009). This underpins the need to know the child well enough to understand triggers and motivations. Linked to this is the child's awareness of the consequences of such actions. Both of the girls' mothers realised that their daughters could inadvertently be disruptive "because 
she wouldn't have known what she was doing" (Georgina's mother), and "it's not poor behaviour, it's a need to express herself orally, but she doesn't always judge her moments correctly" (Francesca's teacher).

\section{Relationships with adults and peers}

A lack of (or poor quality) social relationships are recognised as important risk factors for becoming the victim of bullying (Bauminger et al., 2008), and the resultant isolation and loneliness is likely to intensify this vulnerability. However, all of the children in this study had positive relationships with adults at school: something which has been identified as important for a successful school experience (Dillon et al., 2014; Sciutto et al., 2012). The consistency and fairness that teachers are expected to exemplify were at the core of this. For example, Robbie's mother felt that adults at school "just feel safer to him because they're sort of more authoritative to him." This was also the case for Francesca, who had a very trusting relationship with her form tutor who was "so consistent, absolutely consistent, there is never any variant from the rules". Unfortunately, this positive bond was frequently not replicated in peer relationships, despite parents and teachers noting that the peer group tended to be tolerant and supportive. As the youngest pupil, Robbie appeared to have the fewest difficulties, although his teacher observed that "he doesn't really have relationships with his peers in the same way as other children do because he is very sort of separate." The situation for the older pupils was more complex. Georgina's learning delay meant that there was an ever-increasing gap in maturity between her and her peers: something of which her mother was painfully aware and had led to her opting for a special school once she reached secondary age. Jack appeared to have more positive relationships with his peers due to his interest in football. Indeed, when asked about his friends, the only information Jack offered was that they were "nice", "they like football and that's it." Samuel, however, appeared to 
have been isolated from his peers throughout much of his time at school and he was acutely aware of this. Although in Year 6 he seemed to have made friends with a friend's son, his mother still viewed him as "tagging along in the background."

This separation from peers is an important vulnerability factor for bullying and is inextricably linked to a sense of difference that was identified by parents, staff and some of the older children (e.g. Francesca's teacher: "She is different but she doesn't necessarily want to see herself as different"). Jack had clearly benefited from his interest in football, however, his mother realised that this was not as simple as it may appear superficially, stating: "Socialising and stuff like that, he does find that quite hard sometimes. I think sometimes he almost thinks he doesn't, but you know, when you sort of stand back and watch, sort of as a parent you notice things." Transitions were mentioned by all parents as a source of concern; especially as long-standing relationships were likely to be severed when moving from primary to secondary school, making the young people even more vulnerable to bullies who might be older and unaware of the nature of their difficulties.

These findings resonate with the literature that finds fairly consistently that young people with ASC often struggle with the social demands placed on them: making and maintaining friendships can be problematic (Bauminger et al., 2008), with social vulnerability a powerful predictor of bullying (Sofronoff et al., 2011), and relationship issues hampering the social support that may protect against bullying (Humphrey \& Symes, 2010a).

\section{The role of school}

While academic progress may not immediately appear to be salient in terms of a child's vulnerability to bullying, having appropriate support when at school can help a child to grow in confidence and play a more central part in the class, both of which are likely to protect 
against bullying. The role of the teaching assistant was apparent in relation to the academic progress of the pupils, with Robbie, Georgina and Francesca working closely and collaboratively with them. Nevertheless, there was also the feeling that these three children risked over-reliance on them (e.g. Francesca's teacher: "If she doesn't have an assistant in important classes, she just panics and is very dependent on the assistant"). This was not the case for Jack and Samuel whose parents were keen to point out how the boys were encouraged to develop more independent learning styles. Thus, used appropriately, the teaching assistant's role (or even that of the class teacher in a one to one capacity) was seen very much as that of an enabler and confidence builder in accessing the mainstream curriculum. This finding is consistent with research that has emphasised the central role of school in providing a suitable environment, with a flexible approach (e.g. Morewood, Humphrey, \& Symes, 2011; Wing \& Cigman, 2007).

In addition to academic support, schools were seen to provide significant levels of support to promote the children's skills and enable a sense of inclusion in the life of the school. Georgina's school had a lunch club and a buddy system, whereby children in Year 6 kept an eye on younger, more vulnerable children in the playground, and Samuel's school provided a structured lunchtime games club. Jack's school used solution-focused strategies with vulnerable pupils, and Social and Emotional Aspects of Learning (SEAL) was mentioned in both Robbie's and Samuel's schools in the context of helping with their social skills. Francesca's school had a Hub where more vulnerable pupils could go at lunchtime and socialise in a safe, supported environment.

Despite the successful attempts to monitor and support the pupils in this study during unstructured times of the school day, the children's participation in after-school activities was less common. Georgina and Francesca both struggled with clubs due to being at a different level of emotional and social maturity to the other children, whereas Jack often lacked the 
energy to attend clubs after school, and he was quick to point out that he did not like school because "it's too long, it's six hours." There has been very little research to date on the extracurricular participation of young people with ASC, but the findings in the current study underline the need to understand children's individual needs and not insist on them participating in activities: rather the opportunities need to be present, just as for their peers.

The significance of understanding and acting upon bullying behaviour was highlighted by parents in terms of the school ethos. In particular, the importance of a clear and effective antibullying policy that everyone understood and implemented emerged strongly. For them, this contributed to a strong ethos, and one in which children with specific needs were able to flourish. All of the parents interviewed were unanimous in their support for the schools their children attended, and part of this appears to be due to good levels of communication and the ease with which teachers could be approached (e.g. Jack's mother: "You know, anything, anything you want, if you're worried about anything, you can always come in, which is really good"). These findings link with literature indicating that positive relationships between home and school tend to result in children being more settled and successful academically (Card et al., 2008; Humphrey et al., 2011).

\section{Conclusion}

The aim of this study was to explore vulnerability to bullying and the experience of school from the perspective of children with ASC, their parents and teachers. While this was a small-scale qualitative study that cannot be generalised in isolation, it is of note that the findings mirror and complement a number of the key trends in quantitative studies of bullying, particularly in terms of the key themes of the experience of being bullied, problematic relationships with peers, behaviour difficulties, and the critical role of school. 
Although none of the children in this study had been the victims of serious bullying, all of them apart from the youngest had been subject to low levels of bullying, reinforcing the message from other research (e.g. Reid \& Batten, 2006; Rowley et al., 2012) that this group of young people is particularly vulnerable to bullying by peers, and therefore needs careful monitoring at school, including an individualised approach that takes account of sensory sensitivities and behavioural triggers. Curriculum support can assist in confidence-building, but it is also important to remember that academic success alone does not guarantee a successful school experience. School-based interventions are often needed to ensure that the child has the contact he or she needs, especially at unstructured times of the day, and there are a number of examples given in this study that demonstrate how the risk of isolation from peers can be addressed. As noted in previous studies (e.g. Sciutto et al., 2012), interventions should not only be aimed at the child with ASC, but also at the peer group and teaching staff through the promotion of difference, tolerance and diversity within the curriculum, including a zero tolerance attitude towards all bullying behaviour: something which many successful schools already achieve.

This study has attempted to offer an insight into the school experience from the perspective of children with ASC, their parents and teachers, however there are a number of limitations to be acknowledged. As the participating schools opted into the case study element of the research, it is possible that only those that were confident in their ability to meet the needs of their pupils with SEND volunteered. It is also possible that the schools only proposed the focus pupils if the parents were considered reliable and more likely to speak positively about the school. In addition, despite wishing to include the pupil voice, only three of the five children were able to give informed consent to be interviewed, yielding a relatively limited amount of information compared to the adult interviews. In this context, future studies should aim to include the voice of the young people to a greater extent (e.g. through observation or 
diaries) in order to reflect more fully their perspective of school and bullying. However, involvement in research that explores potentially upsetting topics must be balanced with the need to avoid causing harm or distress to young people. Furthermore, this study only recruited pupils from mainstream schools, and so more research should be encouraged in special school settings, as they remain an under-researched area.

To conclude, it is the authors' contention that qualitative research has a powerful part to play in understanding and addressing the vulnerability to bullying of young people with ASC. Therefore, continued in-depth research is needed in this area that encompasses different stages of development, severity of autism and environment. Given the serious and longlasting effects of bullying, it is clear that it should not be an inevitability for any child, with school playing a vital role in reducing and managing the risk.

\section{References}

Attwood, T. (2007). The Complete Guide to Asperger's Syndrome. London: Jessica Kingsley Publishers.

Baron-Cohen, S. (2012). 'ASD vs. ASC: is one small letter important?' (Conference paper). Paper presented at the Disorder or Difference conference, London.

Bauminger, N., Solomon, M., Aviezer, A., Heung, K., Brown, J., \& Rogers, S. J. (2008). 'Friendship in high-functioning children with autism spectrum disorder: Mixed and non-mixed dyads.' Journal of Autism and Developmental Disorders, 38 (7), pp. 12111229. 
Billington, T. (2006). 'Working with autistic children and young people: sense, experience and the challenges for services, policies and practices.' Disability \& Society, 21 (1), pp. 1-13.

Bölte, S. (2014). 'The power of words: Is qualitative research as important as quantitative research in the study of autism?' Autism, 18 (2), pp. 67-68.

Braun, V., \& Clarke, V. (2006). 'Using thematic analysis in psychology.' Qualitative Research in Psychology, 3 (2), pp. 77-101.

Cappadocia, M. C., Weiss, J. A., \& Pepler, D. (2012). 'Bullying experiences among children and youth with autism spectrum disorders.' Journal of Autism and Developmental Disorders, 42 (2), pp. 266-277.

Card, N. A., Isaacs, J., \& Hodges, E. V. E. (2008). 'Multiple contextual levels of risk for peer victimization: a review with implications for prevention and intervention efforts.' In T. W. Miller (Ed.), School Violence and Primary Prevention (pp. 125-153). New York: Springer Science and Business Media.

Carrington, S., \& Graham, L. (2001). 'Perceptions of school by two teenage boys with Asperger syndrome and their mothers: a qualitative study.' Autism, 5 (1), pp. 37-48.

Chamberlain, T., George, N., Golden, S., Walker, F., \& Benton, T. (2010). Tellus4 National Report (DCSF-RR218). London: National Foundation for Educational Research.

DfE. (2012). 'Children with special educational needs: an analysis.' London: DfE Publications. 
Dillon, Gayle V., Underwood, Jean D. M., \& Freemantle, Lauren J. (2014). 'Autism and the U.K. Secondary School Experience.' Focus on Autism and Other Developmental Disabilities. doi: 10.1177/1088357614539833

Education and Inspections Act (2006).

http://www.legislation.gov.uk/ukpga/2006/40/contents/enacted (accessed 12 October 2014).

Green, R., Collingwood, A., \& Ross, A. (2010). Characteristics of bullying victims in schools. (DfE-RR001). London: DfE.

Greene, J. C., \& Hall, J. N. (2010). 'Dialectics and pragmatism: being of consequence.' In A. Tashakkori \& C. Teddlie (Eds.), Handbook of mixed methods in social and behavioural research (2nd ed., pp. 119-144). Thousand Oaks, CA: Sage.

Hebron, J. S., \& Humphrey, N. (2013). 'Exposure to bullying among students with autism spectrum conditions: A multi-informant analysis of risk and protective factors.' Autism. doi: 1362361313495965

Humphrey, N. (2008). 'Including pupils with autistic spectrum disorders in mainstream schools.' Support for Learning, 23 (1), pp. 41-47.

Humphrey, N., \& Lewis, S. (2008). "'Make me normal": the views and experiences of pupils on the autistic spectrum in mainstream secondary schools.' Autism, 12 (1), pp. 23-46.

Humphrey, N., Squires, G., Barlow, A., Bulman, W. F. L., Hebron, J. S., Oldfield, J., . . Kalambouka, A. (2011). Achievement for All National Evaluation: Final Report. (DfE-RR123). London: DfE. 
Humphrey, N., \& Symes, W. (2010a). 'Perceptions of social support and experiences of bullying among pupils with autism spectrum disorders (ASD) in mainstream secondary schools.' European Journal of Special Needs Education, 25 (1), pp. 77-91.

Humphrey, N., \& Symes, W. (2010b). 'Responses to bullying and use of social support among pupils with autism spectrum disorders (ASDs) in mainstream schools: A qualitative study.' Journal of Research in Special Educational Needs, 10 (2), pp. 8290.

Jackson, L. (2002). Freaks, Geeks \& Asperger Syndrome: A User Guide to Adolescence. London: Jessica Kingsley Publishers.

Klin, A., Volkmar, F. R. , \& Sparrow, S. S. (Eds.). (2000). Asperger Syndrome. New York: Guilford Press.

Kloosterman, P. H., Kelley, E. A., Craig, W. M., Parker, J. D. A., \& Javier, C. (2013). 'Types and experiences of bullying in adolescents with an autism spectrum disorder.' Research in Autism Spectrum Disorders, 7 (7), pp. 824-832.

Leekam, S.R., Nieto, C., Libby, S. J , Wing, L., \& Gould, J.. (2007). 'Describing the Sensory Abnormalities of Children and Adults with Autism.' Journal of Autism and Developmental Disorders, 37 (5), pp. 894-910.

Locke, J., Ishijima, E. H., Kasari, C., \& London, N. (2010). 'Loneliness, friendship quality and the social networks of adolescents with high-functioning autism in an inclusive school setting.' Journal of Research in Special Educational Needs, 10 (2), pp. 74-81.

MacNeil, B. M. , Lopes, V. A., \& Minnes, P. M. (2009). 'Anxiety in children and adolescents with Autism Spectrum Disorders.' Research in Autism Spectrum Disorders, 3 (1), pp. $1-21$. 
McMahon, E. M., Reulbach, U., Keeley, H., Perry, I. J., \& Arensman, E. (2010). 'Bullying victimisation, self harm and associated factors in Irish adolescent boys.' Social Science \& Medicine, 71 (7), pp. 1300-1307.

Morewood, G. D., Humphrey, N., \& Symes, W. (2011). 'Mainstreaming autism: making it work.' Good Autism Practice, 12 (2), pp. 62-68.

Murphy, J., \& Cameron, L. (2008). The effectiveness of talking mats for people with intellectual disability British Journal of Learning Disability, 36, 232-241.

NAS. (2014). What is autism? http://www.autism.org.uk/about-autism/autism-and-aspergersyndrome-an-introduction/what-is-autism.aspx (accessed 12 November 2014).

Olweus, D. (1993). Bullying at school: what we know and what we can do. Oxford: Blackwell.

Reid, B., \& Batten, A. (2006). B is for Bullied. London: National Autistic Society.

Rowley, E., Chandler, S., Baird, G., Simonoff, E., Pickles, A., Loucas, T., \& Charman, T. (2012). 'The experience of friendship, victimization and bullying in children with an autism spectrum disorder: Associations with child characteristics and school placement.' Research in Autism Spectrum Disorders, 6 (3), pp. 1126-1134.

Schroeder, J. H., Cappadocia, M., Bebko, J. M., Pepler, D. J., \& Weiss, J. A. (2014). 'Shedding light on a pervasive problem: a review of research on bullying experiences among children with autism spectrum disorders.' Journal of Autism and Developmental Disorders, 44 (7), pp. 1520-1534.

Sciutto, M., Richwine, S., Mentrikowski, J., \& Niedzwiecki, K. (2012). 'A qualitative analysis of the school experiences of students with Asperger Syndrome.' Focus on Autism and Other Developmental Disabilities, 27 (3), pp. 177-188. 
Smith, J. A., \& Osborn, M. (2008). 'Interpretative Phenomenonological Analysis.' In J. A. Smith (Ed.), Qualitative psychology: a practical guide to research methods (2nd ed.). London: Sage.

Smith, P. K., Cowie, H., Olafsson, R. F., Liefooghe, A. P., Almeida, A., Araki, H., . . . Wenxin, Z. (2002). 'Definitions of bullying: A comparison of terms used, and age and gender differences, in a fourteen-country international comparison.' Child Development, 73 (4), pp. 1119-1133.

Sofronoff, K., Dark, E., \& Stone, V. (2011). 'Social vulnerability and bullying in children with asperger syndrome.' Autism, 15 (3), pp. 355-372.

Sourander, A., Jensen, P., Ronning, J. A., Niemela, S., Helenius, H., Sillanmaki, L., . . Almqvist, F. (2007). 'What is the early adulthood outcome of boys who bully or are bullied in childhood? The Finnish "From a Boy to a Man" study.' Pediatrics, 120 (2), pp. 397-404.

Sreckovic, M. A. , Brunsting, N. C., \& Able, H. (2014). 'Victimization of students with autism spectrum disorder: A review of prevalence and risk factors.' Research in Autism Spectrum Disorders, 8 (9), pp. 1155-1172.

Ttofi, M. M., \& Farrington, D. P. (2011). 'Effectiveness of school-based programs to reduce bullying: A systematic and meta-analytic review.' Journal of Experimental Criminology, 7 (1), pp. 27-56.

Wainscot, J.J., Naylor, P., Sutcliffe, P., Tantam, D., \& Williams, J. (2008). 'Relationships with peers and use of the school environment of mainstream secondary school pupils with Asperger Syndrome (high-functioning autism): a case control study.' International Journal of Psychology and Psychological Theory, 8 (1), pp. 25-38. 
Wing, L., \& Cigman, R. (2007). Included or excluded? The challenge of mainstream for some SEN children.

Zablotsky, B., Bradshaw, C. P., Anderson, C., \& Law, P. A. (2013). 'The association between bullying and the psychological functioning of children with autism spectrum disorders.' Journal of Developmental \& Behavioral Pediatrics, 34 (1), pp. 1-8. 